Gut Festschrift, 1989, 81-84

\title{
A faithful friend is the medicine of life
}

\author{
(Ecclesiasticus 6.16)
}

The practice of medicine in the Dales

J B COLTMAN AND K M D COLTMAN

In some of his articles Christopher Booth has referred to a particular practice in Wensleydale, covering 120) square miles, in the confines of which his parents lived from 1939 onwards. At the time of his retirement, it may be appropriate to consider some aspects of the Aysgarth practice which interested him. His family's cottage situated in Worton, lies three miles west of Aysgarth and was bought by his mother in 1931 as a holiday home for her family of five children, which included two sets of twins. After war broke out it became their principle residence. Chris Booth went to Sedbergh School which, at that time, was within the boundary of the old west riding of Yorkshire. There he was taught, among other things, to speak French fluently and for this he remains grateful. His parents were our patients and despite the stringency of post War rationing we were offered hospitality at the cottage and in 1947 we even received wedding presents. The pattern of his family's life was changed abruptly in 1952, when his mother was found to be hypertensive and died after a relatively short illness. Despite this loss, we remained in touch with the family and attended some of their social occasions. We remember well his father playing music of his own composition, which was later performed on the organ in Askrigg church when one of Christopher's sisters was married. His father lived on, supported by an excellent housckeeper, until 1963, when he died and was buried beside his wife in Aysgarth churchyard.

After Christopher inherited the cottage we came to know him better and watched him develop a love affair with Wensleydale, which still continues. An obvious attraction is the beauty and varicty of the surrounding hills. These are not so huge as to be overwhelming but include accessible heights that can, even before breakfast time, be scaled casily. At the same time, they are sufficiently remote as to remain unspoilt. The local people are naturally friendly and it is refreshing to find that Jack is as good as his master. There is a sense of permanence among old established families who can often trace their ancestory back many centuries. Although occupations may change, the old family names recur.
Despite Christopher's outstanding achievements and the many demands on his time, his visits to Wensleydale at times included a call on the practice house in Aysgarth. At other times he went round to see Dr Pickles, who became the first president of the Royal College of General Practitioners, and with whom we worked for 18 years. His interest in early Wensleydale doctors first arose from his contact with Dr Pickles, whose classic book Epidemiology in country practice was first published in 1939. Christopher's research into the lives of Drs John Fothergill, William Hillary, and Robert Willan is well known and, more recently, he has shown an interest in the work of 20th century general practitioners whose position in society he regards as unique.

After we had been in practice together for over 30) years we were invited to prepare a paper on 'Child care in the country' to present at a day conference for community health councils in the region. This was held at our nearest hospital situated 27 miles away. We had preserved full obstetrical records of about 1000 deliveries undertaken during our years in practice and these figures provided the basis for a discussion on child care. It was no surprise to find that all babies surviving their first week of life were successfully reared, except for two with spina bifida. The shock came in discovering that, despite there

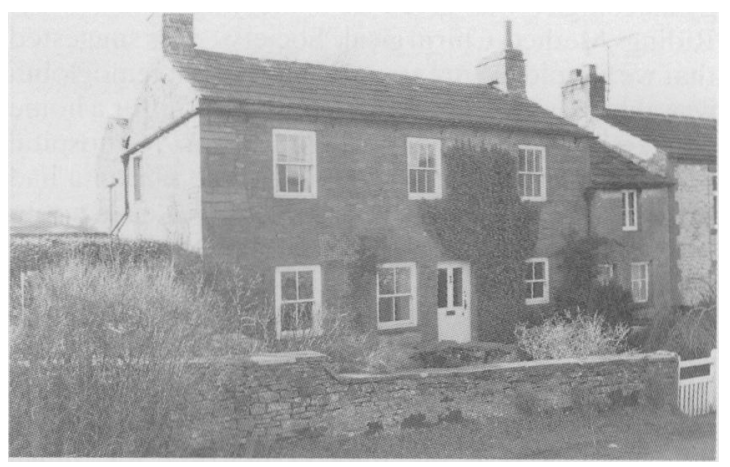

The Cottage at Worton. 


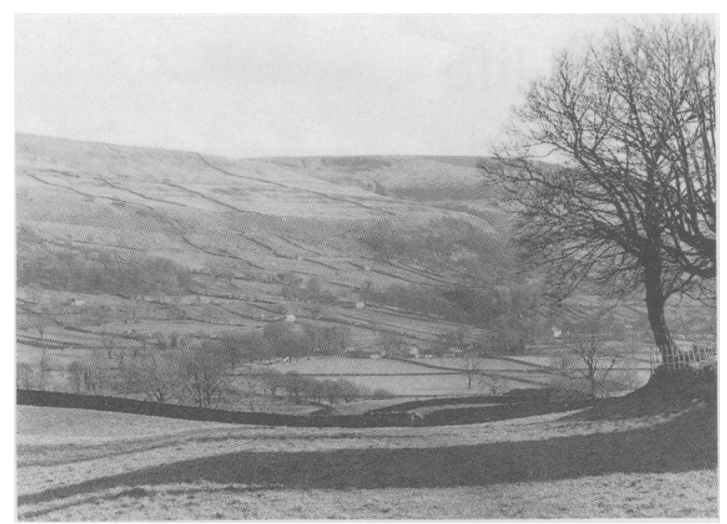

Walden Valley.

being only one still birth in home deliveries, 20 babies had died before they were a week old. Five infants had severe congenital neural tube defects, five were born alive prematurely at a time when survival under $2 \mathrm{~kg}$ was unlikely, and three who were born in hospital because of complications in the mother's pregnancy died during the first week of life. Additionally, five women suffered from recurrent pregnancy loss in hospital without identifiable cause. These figures suggest that antenatal diagnosis of congenital abnormalities and the better facilities now available for the care of premature infants should more than halve the apparent infant loss. One cot death occurred but there was no baby battering, and the sexual abuse of children was never discussed.

Domiciliary midwifery, now an outdated concept, was always interesting and created enduring friendship between the doctor and the family. The third stage of labour was always the most anxious time because once the baby was delivered, the responsibility for the successful completion of the third stage was ours alone and sometimes we were as far as 40 miles from hospital. Some good advice from a gynaecologist was given at a meeting of the West Riding Medico-Chirurgical Society. He suggested that we should ensure that the mother's haemoglobin was always within normal limits and that after a home delivery a woman requiring transfer to hospital should never be transported unless the placenta had been delivered. Having been trained in Leeds not to use ergometrine preparations until after the placenta was delivered, we were forced to perform four manual removals during the first 10 years in practice. When the use of Syntometrine, injected after the delivery of the anterior shoulder became accepted practice, we never had to do another manual removal and blood loss at the time of delivery was much reduced.
Giving further thought to child loss, we found that accidents were the cause of death in five children. Two were from drowning, one was from scalding at four months' old, one was the result of head injury after a fall from a bicycle being ridden down a steep hill, and one was from a shooting accident. Malignant disease and whooping cough accounted for two further deaths. We recall with admiration a widow with two teenage children, who became a housekeeper. She soon produced two little girls. The younger one contracted whooping cough from her elder sister when she was eight weeks' old. The mother sat up day and night for over six weeks and her devotion was crucial in saving the baby's life. Because of her mother's circumstances, the baby was to be offered for adoption but by 14 weeks the bond was so strong that this idea was dropped. She stayed with her mother and although subsequently the family left the area, we heard from the grandparents that they had all prospered. Tuberculous meningitis caused death in a four year old, despite early diagnosis and six months' treatment in hospital with Streptomycin, which had just become available. Bovine tuberculosis in children disappeared a few years later when cows became free from infection.

Immunisation schemes were fully implemented and we never saw diphtheria, tetanus or smallpox and gradually poliomyelitis was eliminated and whooping cough and measles were substantially reduced. A start was made on the problem of rubella. Despite the elimination of many infectious diseases in children and the usefulness of antibiotics. two life threatening infections remained a problem. The early detection of meningitis and acute epiglottitis is not always easy and urgent treatment may be needed. It is relatively easy to promote, administer and perform immunisations, but the prevention of burns, scalds and other accidents in the home and on the road is a more difficult problem. It concerns life styles and doesn't readily fall into the province of primary medical care. Doctors treat the results of accidents to children and see the need for parents to be made aware of dangers in the home but wonder who should do it and how it should be done.

During the years we practised we saw many advances in therapeutics and these are too numerous to mention. Some innovations made a big impression. Our first influenza epidemic was in 1949 and all vulnerable patients and the seriously ill ones received twice daily injections of penicillin. At that time. elderly patients often refused to be nursed in their bedrooms, which were freezingly cold in winter. When oral penicillin and then broad spectrum antibiotics became available and when at last the grid came and bedrooms could be heated electrically, the treatment of chest conditions became simpler. We 
well remember the suffering of patients with unrelieved angina before propranolol was available. When Sir James Black recently received the Nobel prize for medicine we were delighted at the recognition of his achievements. Beta-blocking drugs enabled us, for the first time, to properly control hypertension. Mercurial diuretics were used routinely for peripheral heart failure until we had the thiazides. Patients disliked intensely having to take an ammonium chloride mixture on the days that they had injections. After chlorpromazine and then tricyclic antidepressants were introduced we witnessed a quiet revolution in the treatment of affective disorders. We only had one further suicide.

Changes have also occurred in hospital treatment and in the attitude of patients to hospitals. During our early years, admission to hospital was greatly feared and often regarded as a death sentence, which it sometimes seemed to be. When more consultants were appointed to local hospitals, standards rose and their work was much appreciated by the patients and their doctors. Hip relacement surgery and cardiac surgery have become almost commonplace and many have benefited.

Dales doctors as a whole had a good standing with the consultants. We once looked after a charming, handsome, retired farmer in his 80 s, who suffered a sudden attack of severe melaena and was in extremis when first seen. A new house officer, unfamiliar with the geography of the area, began to argue that his admission was unnecessary and that, in any case, he should be sent somewhere else, west or south, but not east to his local hospital. Eventually, he conceded to our request, the patient was admitted and recovered. Word about our difficulty in arranging admission must have travelled through on the grapevine because ever after that our patients were always admitted without argument. One distinguished surgeon, well known to Christopher, is remembered kindly, not only for his excellent technique, but more particularly because he always got his letters out promptly.

Like all doctors, we have a fund of anecdotes some of which are interesting and others amusing. Unfortunately, these stories sometimes have a cutting edge which means that they are better related than recorded. Some memories, recalled by the woman in the partnership, are known to have intrigued Christopher. A local pathologist who was very deaf once confused my voice with my husband's during a telephone conversation. When I tried to explain which one of us he was speaking to, he brushed aside my remarks saying 'It doesn't matter which one of you it is; I regard the Coltmans as one'. Soon after arriving in Wensleydale, my husband arranged, with some diffidence, for me to see a postman suspected of having a coronary occlusion. During the 1947 snowstorm he had walked many miles every day at heights varying between 800 and $1000 \mathrm{ft}$. The conditions were appalling, because of snow and ice, and there were few mechanical aids to snow clearance. When the physical examination was over he said 'You mun come again' and I presumed that meant he had been embarrassed by having a woman doctor and did not want me to visit again. I was surprised at his frankness and only later realised that 'mun' was a dialect word meaning 'must'. A more bizarre occasion occurred on the one and only time I was called to attend a hanging accident. On arriving at the barn where it happened, the words of a forensic medicine lecturer seemed to ring in my ears - 'First cut down the body'. Realising that my scissors would be inadequate, I said to the boy's father 'can you lend me a knife?'. This remark seemed singularly banal at such a time.

Over 40 years ago we attended a get-together of local general practitioners arranged by Dr Pickles and were introduced to an elderly practitioner from down the dale. He told us, with some glee, that there was nothing new in the book Epidemiology in country practice as the incubation periods of infective hepatitis, measles and other infectious diseases were well known. It was merely the fact that 'Pickles wrote it down' that distinguished him. Soon afterwards we asked a consultant friend if he could suggest any field in which lines of inquiry might be fruitful. Our query was dismissed out of hand, his view being that material available in general practice was unlikely to yield useful results. Thirty years later we made some observations using the McArthur microscope and it became clear that bedside microscopy of freshly passed urine was a useful procedure. Remembering our neighbour's remark, we began to record our findings. Over a period of four years we collected details of about 400 incidents of urinary tract infection in the practice and these provided the basis of a series of articles published in The Practitioner. A visit from the editor convinced him of the originality of the observations and hence it was relatively easy to get the work published. Christopher was delighted to encourage us, and his wife a microbiologist, gave much valuable advice before the first paper was submitted for publication. An advantage of having spent over 30 years in one remote place was that we had a detailed knowledge of the habits, family history, previous illnesses, operations and treatments of patients in the area.

During the early years of our time in Wensleydale our friendship with Christopher was of a desultory nature, but over the the last 20 years it has become more firmly established. Much of his time here was devoted to improving the cottage and rescuing the garden from its neglected state. We often stopped for 
morning coffee when we were on our rounds. He also spent time visiting places of historical interest in the area as he delved into the lives of doctors from the past. He introduced his children to Dales' people and in 1981 mustered together all his brothers and sisters with their spouses and children, and gave a grand party to celebrate 50 years' ownership of the cottage.

We have noticed that invitations to address meetings in the region were nearly always accepted. He spoke at our house to an informed gathering of local practitioners and consultants, he gave a paper at a gastrointestinal symposium at Northallerton, and he was the first speaker at a meeting of the Dales' Doctors' Society held at Castle Bolton. He accepted many other invitations to speak involving an overnight stop in Wensleydale, which indicated that he had a great love for its beauty, its people, and its doctors.

Personal memories in our long association include visions of him when a student, arriving from Scotland on a moped; of his newly fitted DIY kitchen, where he was making plum pies, and of him, looking the part, consuming smoked salmon sandwiches and drinking champagne at Covent Garden. We often saw him at the annual show of the Askrigg Horticultural Society, either presenting cups to the prize winners or admiring the exhibits and enjoying a village tea. We remember with gratitude his visit to a Middlesbrough hospital where one of us was eight weeks into an attack of postinfective polyneuritis and had a tetraparesis and faecal impaction. His return from the shops with All Bran and UHT cream were the turning point in the illness! It was a great surprise and pleasure to see him and Soad at our retirement party in October, 1980.

We regard him as a true friend.

Galloway Rise,

West Burton,

Leyburn, $N$ Yorks 